\title{
Epidural Abscess of the Central Nervous System
}

\author{
Katherine Belden'; Jack Jallo2; Linda Mwamuka² \\ ${ }^{1}$ Department of Infectious Diseases, Thomas Jefferson University, Philadelphia, PA 19107 \\ 2 Department of Neurological Surgery, Vickie and Jack Farber Institute for Neuroscience at \\ Jefferson, Thomas Jefferson University, Philadelphia, PA 19107
}

An epidural abscess is a localized collection of purulent fluid between the dura mater and the overlying vertebral column (spinal epidural abscess) or skull (intracranial epidural abscess). ${ }^{1,2}$ Early diagnosis of epidural abscess is essential as without timely intervention neurologic injury with permanent sequelae can develop. ${ }^{3}$

\section{SPINAL EPIDURAL ABSCESS}

\section{Epidemiology}

Spinal epidural abscess (SEA) is more common than intracranial epidural abscess and is increasing in incidence. In 1975 the reported incidence of SEA was 0.2-2 per 10,000 hospitalized patients. Over the past four decades this has risen to 10-12 per 10,000 hospitalized patients in some referral centers. ${ }^{4-6}$

This increase is likely due to a rising number of patients with risk factors for SEA including intravenous drug use (IVDU), diabetes mellitus, advanced age, renal failure, and compromised immunity as well as degenerative spinal column disease and the growing use of therapeutic spinal interventions including instrumentation, injections, catheter placement and anesthetic procedures. ${ }^{7.8}$ The ongoing opioid epidemic in the United States has had a particular impact on the increased incidence of SEA given the risks of endovascular infection and metastatic seeding associated with intravenous drug use. ${ }^{9}$ The clinical utility of associated risk factors in the diagnosis of SEA in unclear, however, given their apparent absence in 20-50\% of patients. ${ }^{10}$ Detection of SEA with the wide-spread availability of sensitive imaging modalities such as magnetic resonance imaging (MRI) has also improved diagnostic accuracy in recent decades. ${ }^{8}$

\section{Pathophysiology}

One-half of SEA infections are caused by hematogenous spread from a remote site of infection. Common sources include the skin, urinary tract, oral cavity, infection

Table 1. Symptoms of Epidural Abscess at Different Stages [adopted from (20).

\begin{tabular}{l|c|c|c|c|}
\hline Symptom & Stage I & Stage II & Stage III & Stage IV \\
\hline Back or Neck Pain & + & + & + & + \\
\hline Ridiculopathy & - & + & + & + \\
\hline Weakness and/or Bladder Symptoms & - & - & + & + \\
\hline Paralysis & - & - & - & + \\
\hline * Estimates from the original published data by Lee TH et al. Derivation and prospective validation of a simple index \\
for prediction of cardiac risk of major noncardiac surgery. Circulation. 1999 Sep 7; 100(10):1043-9 \\
\# Risk estimates from Duceppe et al. Canadian Cardiovascular Society Guidelines on Perioperative Cardiac Risk \\
Assessment and Mamagement for Patients Who Undergo Noncardiac Surgery. These estimates were based on \\
external validations published after the original study by Lee TH et al (1999).
\end{tabular}

of an indwelling vascular access and endocarditis. ${ }^{3,5,11,12}$ Several regions of the spine may be involved in hematogenous infection. Hematogenous spread via the pelvic cavity's venous drainage system which connects with those of the spine forming Batson's plexus may facilitate infection from a urinary source. ${ }^{13}$

Contiguous extension of infection from osteomyelitis in an adjacent vertebral body or from a psoas or retropharyngeal muscle abscess or decubitus ulcer is estimated to account for up to one-third of infections. ${ }^{3,11}$ Vertebral body infection usually results from hematogenous seeding of the adjacent avascular disc space. $^{12,14}$

Direct inoculation of the epidural space from spinal surgery, injection or catheter placement is another route of infection. Infection can be acquired during the procedure itself or from ascending microorganisms from the skin when a device is retained. $5,15,16$ Additionally, a hematoma secondary to osseous or ligamentous injury can become seeded by bacteria leading to SEA formation. 5 In up to $30 \%$ of patients no source is identified. 5,17,18

Neurologic impairment resulting from SEA is usually the result of spinal cord compression by the infected mass with possible contribution of vascular occlusion. ${ }^{19}$

\section{Clinical presentation}

Four stages of disease severity have been recognized in patients presenting with SEA. ${ }^{20}$ (Table 1) Presentation in stages I or $\mathrm{II}$ is more common, while greater residual deficit is found in those presenting in stages III or IV. Fever is present in $50-60 \%$ of patients while the classic triad of fever, back pain and neurologic deficits is seen in only a minority. ${ }^{21-23}$ Back pain, present in 95\% of patients, with associated nerve root pain, radiculopathy and paresthesia may be the worst of a patient's life, distinct from chronic back pain. Depending on 


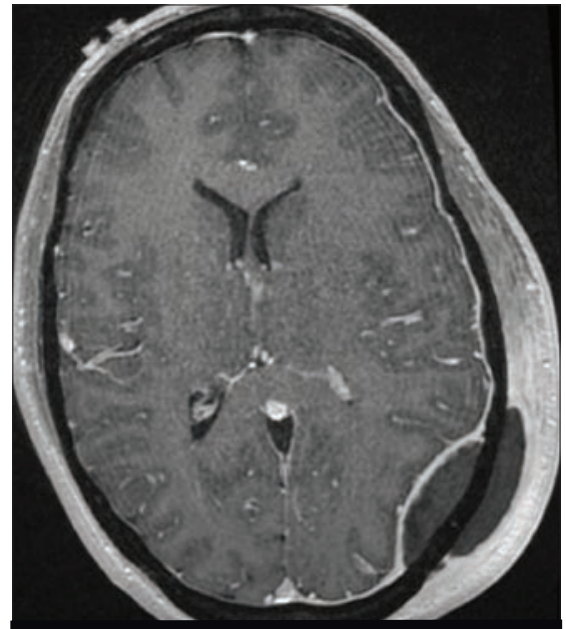

Figure 1a.

T1-weighted axial MRI image showing a left occipital region epidural and extracranial fluid collection/abscess. Reprinted with permission from Priolo SM et al. Acupuncture induced cranial epidural abscess. World Neurosurg 2019 May;125:519-526.

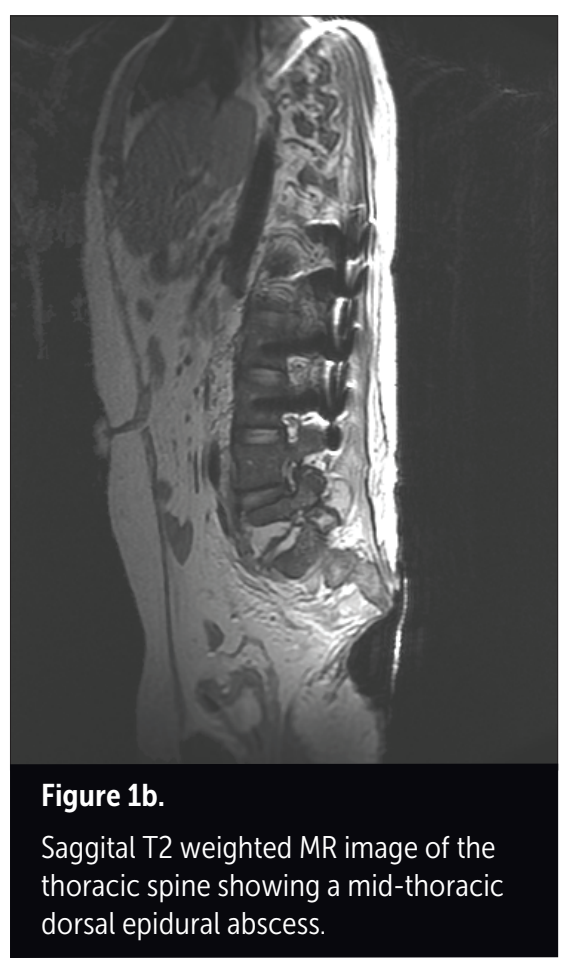

the spine level, pain can radiate to the abdomen, chest or neck, mimicking other conditions. ${ }^{5,18}$ Focal weakness in either the upper or lower extremities is present in $40 \%$ of patients and neurologic deterioration may develop within hours to days or over weeks to months. ${ }^{10,11,18,24}$
Physical examination findings include spinal tenderness in up to $75 \%$ of patients which can be focal or diffuse. Neurologic deficits including spinal cord dysfunction with motor weakness, sensory loss, sphincter dysfunction and paralysis may be found in advanced stage presentation. Once paralysis develops (stage IV), it quickly becomes irreversible, emphasizing the critical need for timely diagnosis. 5,18,24

\section{Diagnosis}

The diagnosis of SEA may be delayed with up to $75 \%$ of cases misdiagnosed on first presentation. Back pain, with a wide differential diagnosis, may be attributed to arthritis or muscular pain.,10 Patients presenting with sepsis and/or altered mental status may be unable to provide a history. ${ }^{25}$ One series looking at 63 patients found that a correct diagnosis of SEA was made after 2 emergency room visits in $51 \%$ of cases, while a further $11 \%$ were identified on a third visit. This is significant as residual motor weakness was identified in up to $45 \%$ of the cohort who experienced delays vs $13 \%$ of those who did not. 22 The increased incidence of SEA has not impacted this diagnostic delay. ${ }^{6,21}$ Recognition of SEA prior to the onset of neurologic symptoms is critical in patients who present with back pain. Diagnosis should be suspected based on clinical presentation and supported with testing. Definitive diagnosis of SEA requires drainage and culture. ${ }^{2}$

\section{Laboratory Testing}

Inflammatory markers including C-reactive protein (CRP) and erythrocyte sedimentation rate(ESR) are sensitive tests for the diagnosis of SEA and are usually elevated with an ESR $>20 \mathrm{~mm} / \mathrm{h}$ reportedly found in $95 \%$ of cases. Leukocytosis is also common, reported in $60-80 \%$ of cases. These tests are not specific for SEA.5,10,26 Blood cultures should be obtained and may be positive in up to $60 \%$ of cases. ${ }^{22,27}$

\section{Imaging Studies}

MRI with gadolinium is the imaging study of choice with a high sensitivity and specificity for detection of SEA (Figure 1b). Imaging the entire spine to exclude noncontiguous SEA is recommended. ${ }^{28} \mathrm{MRI}$ is also the study of choice for detection of vertebral osteomyelitis and/or discitis in patients presenting with back pain. ${ }^{18,29}$ Comparison of $\mathrm{T} 1$ and T2 weighted contrast enhanced images is used in anatomic localization of SEA and to define the extent of infection including assessment for multi-level involvement. ${ }^{30}$

Computed tomography (CT) with intravenous contrast is an alternative diagnostic imaging study with lower sensitivity and specificity than MRI. ${ }^{18}$ Myelography followed by CT scan is a highly sensitive study although an invasive procedure requiring exposure to ionizing radiation with a lower specificity than MRI. Myelography is usually reserved for patients who cannot undergo MRI. Spinal puncture for myelography should be performed distant from the area of suspected infection. 5,17,18 Echocardiography is indicated in all cases of epidural abscess to exclude endocarditis.

\section{Microbiology}

Pathogen identification is very important

\section{Table 2. Pathogens in Spinal Epidural Abscess}

\begin{tabular}{|l|c|}
\hline Pathogen & Percent \% \\
\hline Staphylococcus aureus & $60-90$ \\
\hline Gram-negative bacilli & $10-15$ \\
\hline Streptococcus species & 10 \\
\hline Coagulase-negative staphylococci & $3-6$ \\
\hline Enterococci & $1-2$ \\
\hline Fungi & $1-2$ \\
\hline Anaerobes & $1-2$ \\
\hline Mycobacteria & $<1$ \\
\hline Polymicrobi & $5-10$ \\
\hline Based on references $1,3-7,15,17,18,22,23,25$ & \\
\hline
\end{tabular}


Table 3. Antimicrobial Therapy for Epidural Abscess of the Central Nervous System

\begin{tabular}{|c|c|c|}
\hline Microorganism & First Choice & Alternatives for Anaphylactic Allergy or Resistance. \\
\hline Staphylococci, oxaclllln susceptible & $\begin{array}{l}\text { nafcillin or oxacillin } 2 \mathrm{~g} \mathrm{IV} \mathrm{q4-6} \mathrm{h;} \mathrm{consider} \mathrm{adding} \\
\text { rifampin } 600 \mathrm{mg} \mathrm{PO} \mathrm{q24} \mathrm{h} \mathrm{if} \mathrm{retained} \mathrm{hardware}\end{array}$ & $\begin{array}{l}\text { cefazolin } 2 \mathrm{~g} \text { IV q8 h, vancomycin } 15-20 \mathrm{mg} / \mathrm{kg} \text { IV q12 h or } \\
\text { daptomycin 6-8 mg/kg IV q24 h or linezolid } 600 \mathrm{mg} \text { PO/IV } \\
\text { q12 h; consider adding rifampin } 600 \mathrm{mg} \text { PO q24 h if retained } \\
\text { hardware }\end{array}$ \\
\hline Staphylococci, oxacillin resistant & $\begin{array}{l}\text { vancomycin } 15-20 \mathrm{mg} / \mathrm{kg} \text { IV q12 h, consider adding } \\
\text { rifampin } 600 \mathrm{mg} \text { PO q24 h if retained hardware }\end{array}$ & $\begin{array}{l}\text { daptomycin } 6-8 \mathrm{mg} / \mathrm{kg} \text { IV q24 h or linezolid } 600 \mathrm{mg} \text { PO/ } \\
\text { IV q12 h or trimethoprim-sulfamethoxazole } 5 \mathrm{mg} / \mathrm{kg} \text { IV/ } \\
\text { PO q8-12 h, consider adding rifampin } 600 \mathrm{mg} \text { PO q24 h if } \\
\text { retained hardware }\end{array}$ \\
\hline $\begin{array}{l}\text { Streptococci, confirm susceptlblllty } \\
\text { testing for vlrldans streptococci }\end{array}$ & $\begin{array}{l}\text { penicillin G 18-24 million units IV q24 h continuously } \\
\text { or in } 6 \text { divided doses, or ceftriaxone } 2 \text { g q 12-24 h }\end{array}$ & vancomycin $15-20 \mathrm{mg} / \mathrm{kg} \mathrm{IV} \mathrm{q12} \mathrm{h}$ \\
\hline Enterococci, penicillin susceptible & $\begin{array}{l}\text { penicillin G 20-24 million units IV q24 h continuously } \\
\text { or in } 6 \text { divided doses, or ampicillin sodium 12g IV q24 } \\
\text { h continuouslv or in } 6 \text { divided doses }\end{array}$ & $\begin{array}{l}\text { vancomycin } 15-20 \mathrm{mg} / \mathrm{kg} \text { IV q12 } \mathrm{h} \text { or daptomycin } 6-8 \mathrm{mg} / \mathrm{kg} \\
\text { IV q24 h or linezolid } 600 \mathrm{mg} \text { PO/IV q12 h }\end{array}$ \\
\hline Enterococcl, penicillin resistant & vancomycin $15-20 \mathrm{mg} / \mathrm{kg} \mathrm{IV} \mathrm{q12} \mathrm{h}$ & $\begin{array}{l}\text { daptomycin 8-10 mg/kg IV q24 h or linezolid } 600 \text { mg PO/ } \\
\text { IV q12 h }\end{array}$ \\
\hline Enterococci, vancomycin resistant & daptomycin 10-12 mg/kg IV q24 h & Linezolid 600 mg PO/IV q12 h \\
\hline Cutibacterium acnes & $\begin{array}{l}\text { penicillin G } 20 \text { million units IV q24 h continuously or in } \\
6 \text { divided doses, or ceftriaxone } 2 \mathrm{~g} \text { q12-24 h }\end{array}$ & $\begin{array}{l}\text { vancomycin 15-20 mg/kg IV q } 12 \text { h or daptomycin 6-8 mg/ } \\
\mathrm{kg} \text { IV q24 h or clindamycin 600-900 mg IV q8 h }\end{array}$ \\
\hline $\begin{array}{l}\text { Enterobacteriaceae, confirm } \\
\text { susceptibility testing }\end{array}$ & 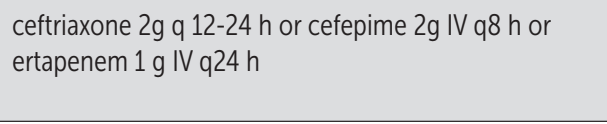 & $\begin{array}{l}\text { meropenem 1-2g q8 h or ciprofloxacin } 400 \text { mg IV q12 h(or } \\
500 \text { mg PO q12 h) or trimethoprim-sulfamethoxazole } 5 \mathrm{mg} / \\
\text { kg IV/PO q8-12 h }\end{array}$ \\
\hline $\begin{array}{l}\text { Enterobacteriaceae, confirm } \\
\text { susceptibility testing }\end{array}$ & $\begin{array}{l}\text { ceftriaxone } 2 \mathrm{~g} \text { q } 12-24 \mathrm{~h} \text { or cefepime } 2 \mathrm{~g} \text { IV q8 h or } \\
\text { ertapenem } 1 \mathrm{~g} \text { IV q24 h }\end{array}$ & $\begin{array}{l}\text { meropenem 1-2g q8 h or ciprofloxacin } 400 \text { mg IV q12 h(or } \\
500 \text { mg PO q12 h) or trimethoprim-sulfamethoxazole } 5 \mathrm{mg} / \\
\text { kg IV/PO q8-12 h }\end{array}$ \\
\hline $\begin{array}{l}\text { Pseudomonas species, confirm } \\
\text { susceptibility testina }\end{array}$ & $\begin{array}{l}\text { cefepime } 2 \mathrm{~g} \text { q } 8 \mathrm{~h} \text {, ceftazidime } 2 \mathrm{~g} \text { q8 } \mathrm{h} \text { or } \\
\text { meropenem } 1-2 \mathrm{~g} \text { q8 } \mathrm{h}\end{array}$ & $\begin{array}{l}\text { azactam } 2 \text { g q8 h or ciprofloxacin } 400 \text { mg IV q8 h (or } 750 \text { mg } \\
\text { PO q12 h) }\end{array}$ \\
\hline $\begin{array}{l}\text { Acinetobacter species, confirm } \\
\text { susceptibility testina }\end{array}$ & meropenem 1-2 g IV q8 h & $\begin{array}{l}\text { ciprofloxacin } 400 \text { mg IV q12 h (or } 500 \text { mg PO q12 h) or } \\
\text { ampicillin- sulbactam 3g/1.5g IV q6 h or polymyxin B 1.5-2.5 } \\
\text { mg/kg IV q24 h in } 2 \text { divided doses }\end{array}$ \\
\hline $\begin{array}{l}\text { Candida species, confirm } \\
\text { susceptibility testina }\end{array}$ & liposomal amohotericinB 5 mg/kg IV q24 h & $\begin{array}{l}\text { fluconazole } 400-800 \mathrm{mg} \text { IV/PO q24 h, consider adding } \\
\text { flucytosine } 25 \mathrm{mg} / \mathrm{kg} \mathrm{q} 6 \mathrm{~h}\end{array}$ \\
\hline
\end{tabular}

in the management of SEA. SEA is most commonly due to Staphylococcus aureus (60-90\% of cases) with methicillin-resistant S. aureus (MRSA) accounting for a significant number of infections, up to $40 \%$ in some series. ${ }^{2,5,17,18}$ Aerobic gramnegative bacilli including Escherichia Coli, Klebsiella spp. and Pseudomonas aeruginosa cause SEA in patients with a history of urinary tract infection and account for 10-15\% of cases. Other pathogens causing SEA include aerobic and anaerobic Streptococcus spp., Enterococcus spp. and coagulasenegative staphylococci with the latter associated with spinal procedures such as the placement of catheters for analgesia, steroid injections, and surgery. Candida spp. are also associated with spinal instrumentation. $5-10 \%$ of infections may be polymicrobic. Atypical pathogens including Brucella species, mycobacteria (tuberculous and non-tuberculous) and fungi can be seen in endemic regions or immunocompromised hosts. 5,17,18 Environmental organisms, for example, the fungus Exerohilum rostratum that was responsible for a multi-state outbreak of spinal infections associated with steroid injections, have been reported with spine innoculation. ${ }^{31}$ Table 2 summarizes the microbiology of SEA.

An intraoperative or image guided sample of the infected fluid should be obtained and sent for culture. Cultures for mycobacteria and fungi and serology for Brucella should be sent if epidemiologic or host risk factors are suggestive of atypical infection. ${ }^{2,32}$ As noted, blood cultures should be obtained and may be positive in up to $60 \%$ of cases. ${ }^{10,17,27}$

\section{Management}

Prompt surgical decompression and abscess drainage is indicated in most cases of SEA to minimize neurologic injury and for control of sepsis. If there are focal neurologic changes, surgical debridement should be performed urgently. ${ }^{5,7,10,33}$ Over the past decade, 
conservative management with antibiotics alone has become more common in patients without neurologic deficits who have an established causative pathogen confirmed either with an image guided aspiration culture or a blood culture growing a virulent pathogen such as S. aureus. The rate of failure with this conservative approach, however, is estimated to be 30-40\% therefore necessitating close monitoring. 7,34,35 Of note, while paraspinal and psoas abscesses and intradiscal spaces are routinely aspirated for microbiologic diagnosis, aspiration and/or drainage of SEA under CT guidance is a technical challenge and only dorsally located SEA without advanced bone destruction on MRI qualify for percutaneous drainage attempt. ${ }^{36}$

As noted in the 2015 Infectious Diseases Society of America guidelines for Native Vertebral Osteomyelitis, empiric antimicrobial therapy should be withheld until after cultures from blood and other possible sources of infection have been obtained except in cases of sepsis or neurologic deficit. ${ }^{29}$ Empiric antimicrobial therapy should include coverage of staphylococci (including MRSA), streptococci and gram-negative pathogens. While the majority of cases of SEA are caused by gram-positive bacteria and therefore empiric coverage for gram-negative organisms may not be necessary in all cases, it is recommended and often implemented. 5,18,29 Vancomycin plus an third or fourth generation cephalosporin or carbapenem (Ceftazidime, Cefepime or Meropenem) is considered first line therapy with alternative coverage for gram-positive organisms including Daptomycin or Linezolid, and alternative coverage for gram-negative organisms including Azactam or Ciprofloxacin. 11,29,32

Once a pathogen is identified, a course of targeted parental or highly bioavailable oral antibiotic therapy is recommended.

(Table 3) While parenteral antibiotic therapy is typically preferred, especially in treating staphylococcal infection, a recently published randomized, noninferiority trial found no difference in the treatment of a variety of bone infections including 39 cases of spinal infection some of whom had SEA, between standard parenteral therapy and an early switch (within 7 days) to oral antibiotic therapy. ${ }^{42}$ Any patient in whom there is a concern for meningitis should be treated with parenteral therapy dosed for CNS penetration for at least 2 weeks. ${ }^{43}$

Recommendations for the duration of therapy for SEA range from 4 weeks to 3-6 months depending on many factors including the concurrent presence of endocarditis, vertebral osteomyelitis and/or retained spinal hardware. 5,29,32,37 Vertebral osteomyelitis commonly occurs with SEA and is usually treated with at least 6 weeks of antibiotic therapy. ${ }^{37-39}$ Few randomized controlled trials(RCT) specifically focusing on the duration of antimicrobial therapy for SEA and/or vertebral osteomyelitis are available. An open-label, non-inferiority, RCT of 359 patients compared 6 weeks of antibiotic therapy to 12 weeks in patients with pyogenic vertebral osteomyelitis finding no difference in cure rate at 1 year. ${ }^{40}$ Information on outcomes with different antimicrobial regimens and durations is often derived from observational studies. ${ }^{14,37,41}$

Some patients may be at higher risk for relapsed SEA and/or vertebral osteomyelitis including those with undrained paravertebral or psoas abscess, concomitant endocarditis, MRSA infection, IVDU, end-stage renal disease, or those with local spinal wound infection. ${ }^{41,44}$ In cases of infection in patients at risk for relapse or related to retained spinal implants extension of antimicrobial therapy (>8 weeks) can be considered. The optimal duration of sequential oral antibiotic suppression in spinal implant infection has not been established but has been shown to decrease the risk of relapse especially in early-onset infections ( $<1$ month from fusion surgery). In delayed onset SEA infections associated with vertebral osteomyelitis, removal of hardware is associated with improved outcomes. $12,39,45$

Patients with SEA should be followed to ensure response to therapy. A 25\% improvement in ESR and CRP at 4 weeks of therapy in combination with improved clinical assessment should be anticipated. A failure of CRP levels to decline can be a poor prognostic marker. ${ }^{16}$ End of treatment imaging is not routinely recommended although a poor clinical response to therapy merits repeat MRI imaging and surgical evaluation. 5,18,46

\section{Outcome}

The most important predicting factor for neurologic outcome in SEA is the patient's neurologic condition prior to surgical decompression. Patients presenting with stage III or IV infection show the worst recovery rate. $4,5,18,47$ An outcome of stable or improved neurologic function in comparison to the preoperative status is anticipated. Patients presenting with paralysis for up to 24-36 hours are expected to regain some neurologic function after surgery and this has been correlated with the rapidity of surgical intervention (within 24 hours). ${ }^{34,47}$ Patients may continue to regain neurologic function and will benefit from rehabilitation through the first year after treatment. ${ }^{34,44}$

Mortality associated with SEA has declined significantly with the availability of advanced cross-sectional imaging, expanded surgical techniques and effective antibiotic therapy. ${ }^{7}$ Death usually results from severe sepsis. Approximately $5-7 \%$ of patients with SEA do not survive in the hospital and 90-day mortality is estimated at $13 \%, 4,7,48$ The best outcomes in the management of SEA are achieved with multidisciplinary care.

\section{INTRACRANIAL EPIDURAL ABSCESS}

\section{Epidemiology}

The incidence of intracranial epidural abscess (ICEA) and its related mortality have decreased since the introduction of antimicrobial therapy. As ICEA can cross the dura via the emissary veins an accompanying subdural empyema is often present. ${ }^{2,49}$

\section{Pathophysiology}

Intracranial epidural abscess (ICEA) can occur following trauma or after neurosurgery including craniotomy, transnasal or transmastoid procedures. Subdural empyema can also result from direct infection of the subdural space during these procedures. ${ }^{2,3}$ ICEA may also develop as a complication of sinusitis, otitis media or mastoiditis and this route of infection is more common in children and young adults. Valveless, bidirectional blood flow 
between the frontal sinus mucosa and dural venous drainage is more common in children given their highly vascular diploic bone. Drainage empties into the superior sagittal sinus, increasing the risk of subdural extension. ${ }^{49,50}$ While longitudinal spread is common in SEA, ICEA without subdural empyema is usually a localized, slowly expanding lesion that rarely extends into the spinal column given the tight adherence of the dura around the foramen magnum. ${ }^{50}$

\section{Clinical Presentation}

Presentation includes fever and headache with variation in time to presentation. Concern for sinusitis and otitis media at presentation may distract from the appropriate diagnosis of ICEA. Periorbital cellulitis and frontal edema are commonly seen. ${ }^{2,3,51}$ ICEA without subdural empyema may present with insidious onset as the space between the dura and cranium is contained, limiting abscess expansion and delaying the development of focal neurologic changes. ${ }^{2}$ If a cranial subdural empyema is also present, however, deeper extension of the infection may lead to more rapid neurologic findings. Epidural abscess after neurosurgery can present with rapid progression given the risk of subdural involvement. 3,16 With or without a subdural empyema, ICEA will eventually lead to neurologic changes with possible seizures as well as signs of increased intracranial pressure including papilledema. 2,3,51 Gradenigo syndrome, unilateral facial pain and weakness with involvement of cranial nerves $\mathrm{V}$ and $\mathrm{VI}$, can develop in patients with otitis media and/ or mastoiditis as ICEA extends along the temporal bone. ${ }^{2,52}$ Both cranial epidural abscess and subdural empyema can be complicated by meningitis, cortical venous thrombosis and brain abscess. ${ }^{53,54}$

\section{Diagnosis}

\section{Laboratory testing}

Laboratory testing in evaluation for ICEA is non-specific. Leukocytosis may be present.

\section{Imaging Studies}

MRI with gadolinium enhancement is the imaging study of choice in evaluation for ICEA. An area of diminished intensity is seen on (Figure 1a) T1 weighted images with hyperintense patterns and pachymeningeal enhancement on T2 weighted images. ${ }^{55}$ Gadolinium enhancement helps to differentiate infected fluid from hematoma or sterile collections that can be seen after trauma or neurosurgery. The presence of subdural empyema, brain abscess or other pathology can also be assessed with MRI. Of note, ICEA can cross the midline of the brain which subdural empyema typically does not. 2,3,50,55 CT scan is less sensitive although can be used to assess bone and may detect a low attenuation extra-axial mass. ${ }^{3}$

\section{Microbiology}

Common causative pathogens in ICEA arising after neurosurgery include Staphylococcus aureus, coagulase-negative staphylococci and gram-negative bacilli. Infection arising from the paranasal sinuses or ear is typically caused by aerobic and anaerobic Streptococcus spp., anaerobic gram-negative bacilli including Bacteroides spp., and S. aureus. While no one organism predominates in this setting, Streptococcus anginosus is common. Infection may be polymicrobic. Pseudomonas aeruginosa infection can arise from otitis media and fungal infection can arise from chronic sinusitis. 3,50

\section{Management}

Given the risk of progression and neurologic deterioration in ICEA, surgical intervention should be undertaken at the earliest sign of worsened neurologic status. Combined neurosurgical and otolaryngologic approaches may be needed. Open or minimally invasive craniotomy for drainage of ICEA are options depending on the location and degree of bone involvement. Single burr hole drainage may be associated with recurrence. Cranialization of the frontal sinus may be indicated in patients with ICEA secondary to frontal sinusitis. 3,56

Patients presenting with a small ICEA can be treated with antimicrobial therapy with close observation and serial imaging to monitor response. Empiric antimicrobial therapy should target the anticipated pathogens causing ICEA including aerobic and anaerobic cocci and bacilli with adequate central nervous system penetration. 3,50,51 Antimicrobial therapy should be tailored based on available microbiologic testing of abscess fluid with confirmation of antibiotic susceptibilities (Table 3 ).
Treatment duration for ICEA has not been established. Extended duration is typically preferred and can be extrapolated from the treatment of brain abscess with courses of 4-6 weeks often used including at least 2 weeks of parenteral therapy. ${ }^{43,50,57}$

\section{Outcome}

The availability of antimicrobial therapy and advances in neuroimaging have decreased morbidity and mortality from ICEA. Poor prognosis is associated with diagnostic delay in patients presenting with vague symptoms as well as brain herniation. ${ }^{2,3}$ The absence of severe neurologic deficits on presentation, minimal co-morbid conditions and young age are associated with improved outcomes.

\section{REFERENCES}

1. Babic M, Simpfendorfer CS. Infections of the Spine. Infect Dis Clin North Am. 2017. doi:10.1016/j.idc.2017.01.003

2. Bennett JE, Dolin R, Blaser MJ. Mandell, Douglas, and Bennett's Principles and Practice of Infectious Diseases.; 2014. doi:10.1093/ jac/46.2.343

3. Pradilla G, Ardila GP, Hsu W, Rigamonti D. Epidural abscesses of the CNS. Lancet Neurol. 2009. doi:10.1016/S1474-4422(09)70044-4

4. Vakili M, Crum-Cianflone NF. Spinal Epidural Abscess: A Series of 101 Cases. Am J Med. 2017. doi:10.1016/j.amjmed.2017.07.017

5. Sendi P, Bregenzer T, Zimmerli W. Spinal epidural abscess in clinical practice. QJM. 2008. doi:10.1093/qjmed/hcm100

6. Artenstein AW, Friderici J, Holers A, Lewis D, Fitzgerald J, Visintainer P. Spinal epidural abscess in adults: A 10-year clinical experience at a tertiary care academic medical center. Open Forum Infect Dis. 2016. doi:10.1093/ofid/ofw191

7. Babic M, Simpfendorfer CS, Berbari EF. Update on spinal epidural abscess. Curr Opin Infect Dis. 2019. doi:10.1097/ QC0.0000000000000544

8. Strauss I, Carmi-Oren N, Hassner A, Shapiro M, Giladi M, Lidar Z. Spinal epidural abscess: In search of reasons for an increased incidence. Isr Med Assoc J. 2013.

9. DiGiorgio AM, Stein R, Morrow KD, Robichaux JM, Crutcher CL, Tender GC. The increasing frequency of intravenous drug abuse-associated spinal epidural abscesses: A case series. Neurosurg Focus. 2019. doi:10.3171/2018.10.FOCUS18449

10. Bond A, Manian FA. Spinal epidural abscess: A review with special emphasis on earlier diagnosis. Biomed Res Int. 2016 doi:10.1155/2016/1614328

11. Krishnamohan P, Berger JR. Spinal Epidural Abscess. Curr Infect Dis Rep. 2014 doi:10.1007/s11908-014-0436-7 
12. Zimmerli W. Vertebral osteomyelitis. N Engl J Med. 2010. doi:10.1056/NEJMcp0910753

13. Cheung WY, Luk KDK. Pyogenic spondylitis. Int Orthop. 2012. doi:10.1007/s00264-011-1384-6

14. McHenry MC, Easley KA, Locker GA. Vertebral Osteomyelitis: Long-Term Outcome for 253 Patients from 7 Cleveland-Area Hospitals. Clin Infect Dis. 2002. doi:10.1086/340102

15. M.E.G.A.S.E.S. Spinal epdiural abscesses in adults: Review and report of iatrogenic cases. Scand J Infect Dis. 1990.

16. Grewal S, Hocking G, Wildsmith JAW. Epidural abscesses. Br J Anaesth. 2006. doi:10.1093/ bja/ael006

17. DiNubile MJ. Spinal epidural abscess. In: Clinical Infectious Disease, Second Edition. ; 2015. doi:10.1017/CBO9781139855952.089

18. Darouiche RO. Spinal epidural abscess. N Engl J Med. 2006. doi:10.1056/NEJMra055111

19. Feldenzer JA, McKeever PE, Schaberg DR, Campbell JA, Hoff JT. The pathogenesis of spinal epidural abscess: Microangiographic studies in an experimental model. J Neurosurg. 1988. doi:10.3171/ jns.1988.69.1.0110

20. HEUSNER AP. Nontuberculous spinal epidural infections. N Engl J Med. 1948. doi:10.1056/ NEJM194812022392301

21. Alerhand S, Wood S, Long B, Koyfman A. The time-sensitive challenge of diagnosing spinal epidural abscess in the emergency department. Intern Emerg Med. 2017. doi:10.1007/s11739017-1718-5

22. Davis DP, Wold RM, Patel RJ, et al. The clinical presentation and impact of diagnostic delays on emergency department patients with spinal epidural abscess. J Emerg Med. 2004. doi:10.1016/j.jemermed.2003.11.013

23. Adogwa O, Karikari IO, Carr KR, et al. Spontaneous spinal epidural abscess in patients 50 years of age and older: A 15-year institutional perspective and review of the literature: Clinical article. J Neurosurg Spine. 2014. doi:10.3171/2013.11.SPINE13527

24. Defroda SF, Depasse JM, Eltorai AEM, Daniels $\mathrm{AH}$, Palumbo MA. Evaluation and management of spinal epidural abscess. J Hosp Med. 2016. doi:10.1002/jhm.2506

25. Pradilla G, Nagahama Y, Spivak AM, Bydon A Rigamonti D. Spinal epidural abscess: Current diagnosis and management. Curr Infect Dis Rep. 2010. doi:10.1007/s11908-010-0140-1

26. Tang HJ, Lin HJ, Liu YC, Li CM. Spinal Epidural Abscess-Experience with 46 patients and evaluation of prognostic factors. J Infect. 2002. doi:10.1053/jinf.2002.1013

27. Curry WT, Hoh BL, Amin-Hanjani S, Eskandar EN. Spinal epidural abscess: Clinical presentation, management, and outcome. Surg Neurol. 2005. doi:10.1016/j.surneu.2004.08.081

28. Ju KL, Kim S Do, Melikian R, Bono CM, Harris MB. Predicting patients with concurrent noncontiguous spinal epidural abscess lesions. Spine J. 2015. doi:10.1016/j. spinee.2014.06.008
29. Berbari EF, Kanj SS, Kowalski TJ, et al. 2015 Infectious Diseases Society of America (IDSA) Clinical Practice Guidelines for the Diagnosis and Treatment of Native Vertebral Osteomyelitis in Adultsa. Clin Infect Dis. 2015 doi:10.1093/cid/civ633

30. Tins BJ, Cassar-Pullicino VN. MR imaging of spinal infection. Semin Musculoskelet Radiol. 2004. doi:10.1055/s-2004-835362

31. Kauffman CA, Pappas PG, Patterson TF. Fungal infections associated with contaminated methylprednisolone injections. N Engl J Med. 2013. doi:10.1056/NEJMra1212617

32. Berbari EF, Kanj SS, Kowalski TJ, et al. 2015 Infectious Diseases Society of America (IDSA) Clinical Practice Guidelines for the Diagnosis and Treatment of Native Vertebral Osteomyelitis in Adults. Clin Infect Dis. 2015;61(6):e26-e46. doi:10.1093/cid/civ482

33. Patel AR, Alton TB, Bransford RJ, Lee MJ, Bellabarba CB, Chapman JR. Spinal epidural abscesses: Risk factors, medical versus surgical management, a retrospective review of 128 cases. Spine J. 2014. doi:10.1016/j. spinee.2013.10.046

34. Tuchman A, Pham M, Hsieh PC. The indications and timing for operative management of spinal epidural abscess: Literature review and treatment algorithm. Neurosurg Focus. 2014. doi:10.3171/2014.6.FOCUS14261

35. Butler JS, Shelly MJ, Timlin M, Powderly WG, O'Byrne JM. Nontuberculous pyogenic spinal infection in adults: A 12-year experience from a tertiary referral center. Spine (Phila Pa 1976). 2006. doi:10.1097/01 brs.0000244662.78725.37

36. Ran B, Chen XR, Zhong Q, Fu M, Wei J. $C T$-guided minimally invasive treatment for an extensive spinal epidural abscess: a case report and literature review. Eur Spine J. 2018. doi:10.1007/s00586-017-5307-0

37. Roblot F, Besnier JM, Juhel L, et al. Optimal Duration of Antibiotic Therapy in Vertebral Osteomyelitis. Semin Arthritis Rheum. 2007. doi:10.1016/j.semarthrit.2006.09.004

38. Lazzarini L, Lipsky BA, Mader JT. Antibiotic treatment of osteomyelitis: What have we learned from 30 years of clinical trials? Int J Infect Dis. 2005. doi:10.1016/j.jij.2004.09.009

39. \&Na; vertebral osteomyelitis: long-term outcome for 253 patients from 7 cleveland-area hospitals. Infect Dis Clin Pract. 2002;11(3):169-170. doi:10.1097/00019048200203000-00027

40. Bernard L, Dinh A, Ghout I, et al. Antibiotic treatment for 6 weeks versus 12 weeks in patients with pyogenic vertebral osteomyelitis: An open-label, non-inferiority, randomised, controlled trial. Lancet. 2015. doi:10.1016/ S0140-6736(14)61233-2

41. Park $\mathrm{KH}, \mathrm{Cho} \mathrm{OH}$, Lee $\mathrm{JH}$, et al. Optimal duration of antibiotic therapy in patients with hematogenous vertebral osteomyelitis at low risk and high risk of recurrence. Clin Infect Dis. 2016. doi:10.1093/cid/ciw098

42. Li H-K, Rombach I, Zambellas R, et al. Oral versus Intravenous Antibiotics for Bone and Joint Infection. N Engl J Med. 2019;380(5):425436. doi:10.1056/NEJMoa1710926
43. Tunkel AR. Brain Abscess. In: Mandell, Douglas, and Bennett's Principles and Practice of Infectious Diseases. ; 2014 doi:10.1016/B978-1-4557-4801-3.00092-8

44. Shah AA, Yang H, Ogink PT, Schwab JH. Independent predictors of spinal epidural abscess recurrence. Spine J. 2018. doi:10.1016/j.spinee.2018.03.023

45. Kowalski TJ, Berbari EF, Huddleston PM Steckelberg JM, Mandrekar JN, Osmon DR. The Management and Outcome of Spinal Implant Infections: Contemporary Retrospective Cohort Study. Clin Infect Dis. 2007 doi:10.1086/512194

46. Kowalski TJ, Berbari EF, Huddleston PM Steckelberg JM, Osmon DR. Do Follow-Up Imaging Examinations Provide Useful Prognostic Information in Patients with Spine Infection? Clin Infect Dis. 2006 doi:10.1086/505118

47. Darouiche RO, Hamill RJ, Greenberg SB, Weathers SW, Musher DM. Bacterial spinal epidural abscess: Review of 43 cases and literature survey. Med (United States). 1992 doi:10.1097/00005792-199211000-00004

48. Shah AA, Ogink PT, Harris MB, Schwab JH Development of predictive algorithms for pretreatment motor deficit and 90-day mortality in spinal epidural abscess. J Bone Jt Surg Am Vol. 2018. doi:10.2106/JBJS.17.00630

49. Albu S, Tomescu E, Bassam S, Merca Z. Intracranial complications of sinusitis. Acta Otorhinolaryngol Belg. 2001 doi:10.1288/00005537-199111000-00016

50. Blank M, Tunkel AR. Infections of the Central Nervous System. In: Pathy's Principles and Practice of Geriatric Medicine: Fifth Edition. 2012. doi:10.1002/9781119952930.ch117

51. Fountas KN, Duwayri Y, Kapsalaki E, et al. Epidural Intracranial Abscess as a Complication of Frontal Sinusitis: Case Report and Review of the Literature. South Med J. 2004. doi:10.1097/01. SMJ.0000117331.31320.83

52. Valles JM, Fekete R. Gradenigo syndrome: Unusual consequence of otitis media. Case Rep Neurol. 2014. doi:10.1159/000365843

53. Sun J, Sun J. Intracranial complications of chronic otitis media. Eur Arch Oto-RhinoLaryngology. 2014. doi:10.1007/s00405-0132778-4

54. Pradilla G, Ardila GP, Hsu W, Rigamonti D. Epidural abscesses of the CNS. Lancet Neurol. 2009. doi:10.1016/S1474-4422(09)70044-4

55. Tsuchiya K, Osawa A, Katase S, Fujikawa A, Hachiya J, Aoki S. Diffusion-weighted MRI of subdural and epidural empyemas. Neuroradiology. 2003. doi:10.1007/s00234003-0949-5

56. Yilmaz N, Kiymaz N, Yilmaz C, et al. Surgical treatment outcome of subdural empyema: A clinical study. Pediatr Neurosurg. 2006. doi:10.1159/000094065

57. Brouwer MC, Tunkel AR, McKhann GM, Van De Beek D. Brain abscess. N Engl J Med. 2014. doi:10.1056/NEJMra1301635 